\section{E-MRS Provisional Executive Committee Proposes Committee Members and Delegates}

Having submitted the statutes and legalized the European Materials Research Society (E-MRS) in early 1986, the E-MRS Provisional Executive Committee is establishing the organization and officers of EMRS in accordance with its statutes. The statutes include a provisional two-level structure: a Provisional Executive Committee consisting of a limited number of members and a Provisional Assembly of Delegates composed of up to 60 members.

The E-MRS Provisional Executive Committee proposes the following:

Provisional Executive Committer members: M. von Allmen, M. Balkanski, G. Bentini, J. B $\phi$ ttiger, A.G. Cullis, H.S. Fredriksson, S. Kalbitzer, E.F. Krimmel, V.T. Nguyen, P. Pinard, M. Rodot, P. Siffert, and B. Stritz- ker; one representative of the European Council (J.P. Massué), European Commission (J.G. Wurm), and EPS (to be nominated), respectively.

Provisional Assembly of Delegntes:

P. Siffert, J.P. Massué, J.G. Wurm, V.T Nguyen, M. Balkanski, S. Kalbitzer, D. Bäuerle, L. Laude, J. B $\phi$ ttiger, F. AgulloLopez, A.G. Cullis, M. Rodot, J.F. McGlip, G. Bentini, P.F. Bongers, J.C. Soares, M. von Allmen, H.S. Fredriksson, E.F. Krimmel, P. Pinard, J.Th.M. De Hosson, P.A. Glasow, M. Cardona, E. Rimini, B. Stritzker, Dr. Altenpohl, F. Buchy, and E. Sirtl.

Each national representative should suggest names from which the Provisional Executive Committee can select to complete the Provisional Assembly of Delegates. According to the statutes the elections conducted by the General Assembly must be held within two years.

The Provisional Executive Committee proposes a scope of duties for its members to the Provisional Assembly of Delegates. This proposal must be presented in the next meeting of Provisional Assembly of Delelgates:

(1) Appointment of a permanent Executive Director (older, experienced scientist)

(2) Long-term planning: A.G. Cullis and B. Stritzker

(3) Finances, budget I, II, III: P. Pinard

(4) National societies: A. G. Cullis and B. Kalbitzer

(5) External contacts: G. Bentini, V.T. Nguyen and P. Siffert

(6) Industries: E.F. Krimmel and H.S Fredriksson; (A. Golanski, C. Hill, J.C. Meijer, and Dr. Nobili)

(7) Rules for symposia chairpersons: H.S. Fredriksson

(8) Publications: $M$. von Allmen

(9) Meetings of the Provisional Executive Committee to take place separately from the Meeting of the Provisional Assembly of Delegates.

\section{Commission of the European Communities Seeks Proposals for Advanced Materials Research}

The Commission of the European Communities invites proposals for participation in a multi-annual research and development program on advanced materials. EURAM, for European Research on Advanced Materials, will have a total budget of 30 million ECU. *

The program's main objective is the development of advanced materials by combining basic research with the engineering development in order to help raise the technological and competitive level of the European Communities' manufacturing industries. This means the creation, development, and use of new materials and the upgrading of more conventional materials to a higher level of sophistication at competitive production costs.

The EURAM program covers three main research areas:

- Metallic materials

Aluminum, magnesium and titanium alloys

High-performance magnetic materials

Electrical and electronic contact materials

Surface coating materials

Thin-walled castings

- Engineering ceramics

Optimization of engineering ceramics

Metal/ceramic interface
Composite ceramics

High-temperature behavior of engineering ceramics

- Composite materials

Organic matrix composites

Metallic matrix composites

Ceramic matrix composites

These research topics have been further subdivided to cover fundamental aspects (theory, crystallography, kinetics, etc.), laboratory experiments (product synthesis, characterization, and testing), and materials production engineering (pilot experiments, economical production processes, and design methodology for high mechanical performance).

The program will be carried out principally through cost-shared research contracts where the European Community contribution will generally be $50 \%$ of the overall cost. The duration of the contracts will not exceed 36 months The deadline for submitting proposals is October 17, 1986

For a detailed description of objectives and research topics and for proposal forms, contact Commission of the European Communities, 200, rue de la Loi, B-1049 Brussels, DG XII/G--EURAM Progam; telephone for general information: (2) 235-70-62; telephone for technical information: (2) 235-52-90.

\section{E-MRS}

For further
information
about E-MRS
activities
contact:

P. Siffert

Centre de Recherches

Nucleaires

Laboratoire PHASE 67037 Strasbourg Cedex

France

Telephone: (88) 286543 